\title{
Opportunities to improve grazing management
}

\author{
S. McCARTHY ${ }^{1}$, C. HIRST $^{2}$, D. DONAGHY 2 , D. GRAY ${ }^{2}$ and B. WOOD ${ }^{2}$ \\ ${ }^{1}$ DairyNZ, Private Bag 3221, Hamilton 3240, New Zealand \\ ${ }^{2}$ Massey University, Private Bag 11222, Palmerston North 4442, New Zealand
}

Sean.mccarthy@dairynz.co.nz

\begin{abstract}
Improved efficiency in growing and converting pasture into product is required to maintain New Zealand's competitive advantage in dairying. This study focused on two areas of grazing management, the first an assessment of the indicators leaf stage, pre-grazing yield and grazing residual. In summary, $49 \%$ of measured paddocks were grazed too soon based on leaf stage, $62 \%$ were grazed outside the recommended pre-grazing yield, and $48 \%$ of measured paddocks were not grazed to a desirable height. The second part of the study provided an insight into farmer decision making at an operational level of grazing management with three key components identified. These were: 1) The recruitment of paddocks into a grazing plan; 2) The shuffling of the paddock grazing sequence within the grazing plan; and 3) The management of individual grazing events before, during and after the event. An improved understanding by rural professionals of grazing management decision making would result in extension strategies which generate increased farmer engagement, adoption of grazing management technologies and improved onfarm productivity.
\end{abstract}

Keywords: dairy, grazing management

\section{Introduction}

With growing environmental concerns and the need to remain focused on New Zealand's competitive advantage in dairying, improved efficiency in growing and converting pasture into product is required. Trends towards improved nutrient use, higher per cow performance from grazed grass, and the increased use of supplements make decision making at an operational feed management level more crucial to maintaining profitability. Operational grazing management is the process of making paddock grazing plans and subsequently implementing and controlling those plans. It is highly frequent, repetitive and continuous as grazing events occur twice a day on most farms. These decisions enable farmers to deal with the challenges presented by fluctuating grass dry matter availability between paddocks, due to a range of factors including farm infrastructure, topography or climatic variability.

Macdonald et al. (2010) stated that there are three key grazing management decisions. These are: 1) when to graze, which determines grazing interval, 2) how hard to graze, which determines the grazing intensity, and 3) how long to graze, which determines the grazing duration. The height to which swards are defoliated (i.e. the post-grazing residual) can affect animal performance (Ganche et al. 2013), grass dry matter (DM) yield, sward structure and quality of subsequent available pasture (Hoogendoorn et al. 1988; Macdonald et al. 2010). The effect of pre-grazing DM yield on animals and plants is also well recognised (Holmes et al. 1992; Macdonald et al. 2010). Leaf regrowth stage is a useful parameter to indicate the readiness of the plant to be grazed in terms of nutrient content, as well as regrowth potential (Fulkerson \& Donaghy 2001). Therefore the assessment of these indicators on-farm provides a useful insight into the effectiveness of grazing management decisions and an indication of the potential pasture and animal performance which is being realised.

This study focused on two areas, firstly, an assessment of the indicators of grazing management leaf stage, pre-grazing DM yield and grazing residual, and secondly, farmer decision making, at an operational level, in relation to grazing management.

\section{Materials and Methods}

The first part of the study involved monitoring seven dairy farms in the Lower North Island every 2 weeks, from August 2012 to May 2013, to capture the outcomes of existing pasture management approaches and decision making. At each monitoring event, the next three paddocks to be grazed were assessed for pre-grazing cover and the last three paddocks grazed for post-grazing residual. Forty measurements per paddock were taken using a rising plate meter with an electronic counter (Farmworks, Palmerston North, New Zealand) and DM yield estimated using the winter calibration equation $(0.5 \mathrm{~cm}$ units or clicks $\times 140+500)$. Leaf growth stage was also recorded on pre-grazing paddocks on 10 randomly selected tillers per paddock using the method of Donaghy (1998). On each farm, an average of 53 pre-grazing yield and leaf growth stage and 55 post-grazing residual measurements were taken.

The second part of the study involved field observations of two farmers, each at six grazing events, to assess their grazing management decision making. 


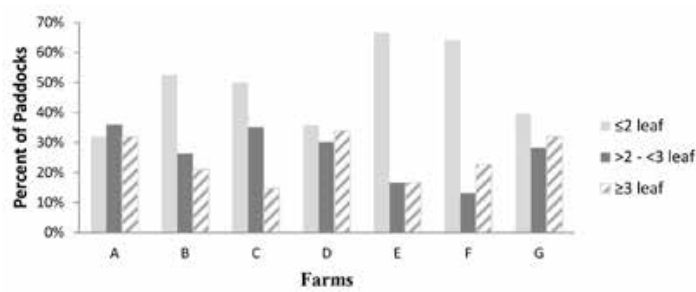

Figure 1 The proportion of paddocks grazed according to leaf regrowth stage ( $\leq$ the 2-leaf, between the 2- and 3-leaf, or $\geq$ the 3-leaf regrowth stages), on seven case study farms between August 2012 and May 2013.

Farmers were questioned about the processes used to ascertain their decision making pathway. These interviews were recorded, transcribed and analysed using qualitative data analysis techniques (Dey 1993) to develop a model of these farmers' processes.

\section{Results and Discussion}

From the assessment of grazing management indicators, it was found that $49 \%$ of paddocks were grazed at or prior to the two-leaf stage, $27 \%$ between the two- and three-leaf stages and $25 \%$ at or beyond the three-leaf stage (Figure 1). Grazing intervals on Farms $\mathrm{E}$ and $\mathrm{F}$ were notably shorter than on other farms, with grazing occurring before or at the two-leaf stage for over $60 \%$ of grazing events.

Leaf regrowth stage is an indicator of herbage mass accumulation, with leaf stages 1,2 and 3 associated with $15,35-40$ and $45-50 \%$ of total herbage accumulation (Lee et al. 2010). Grazing perennial ryegrass pastures close to the three-leaf stage maximises pasture regrowth and quality (Fulkerson \& Donaghy 2001). Grazing before the two-leaf stage reduces the phase of rapid growth, reducing total pasture accumulation and also reducing the replenishment of water soluble carbohydrates reserves, therefore reducing the ability of plants to tiller and to survive during stress periods (Donaghy \& Fulkerson 1998). Plants should only be grazed before the two-leaf stage if canopy closure has occurred or if a reduction in growth rates is desirable. The data would suggest that there is significant opportunity to extend the grazing interval and increase the amount of pasture grown on the case study farms. This increase would be in the order of 4 to 6 days in summer to grow an additional half of a leaf (Lee $\mathrm{et}$ al. 2011).

Pre-grazing yield measurements indicated that 21\% were grazed at greater than $3200 \mathrm{~kg} \mathrm{DM} / \mathrm{ha}, 38 \%$ at between 2600 and $3200 \mathrm{~kg} \mathrm{DM} / \mathrm{ha}$ and $43 \%$ at less than $2600 \mathrm{~kg} \mathrm{DM} / \mathrm{ha}$ (Figure 2).

DairyNZ recommendations are to graze perennial ryegrass based pastures between 2600 and $3200 \mathrm{~kg}$ $\mathrm{DM} /$ ha (DairyNZ 2008) during the main grazing period.

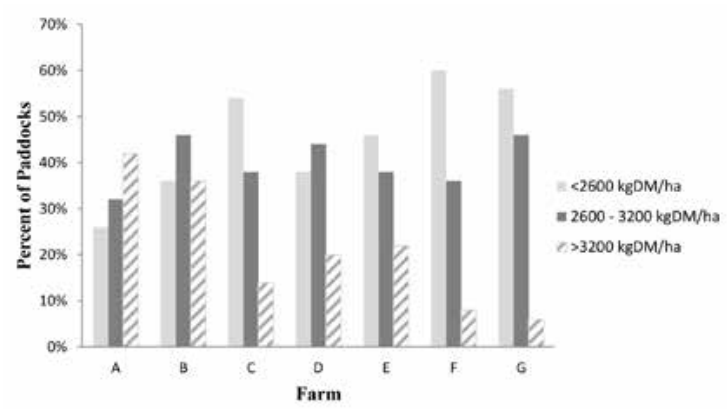

Figure 2 The proportion of paddocks grazed according to pre-grazing herbage mass ( $<2600$, between 2600 and 3200 , or $>3200 \mathrm{~kg}$ dry matter (DM)/ha), on seven case study farms between August 2012 and May 2013.

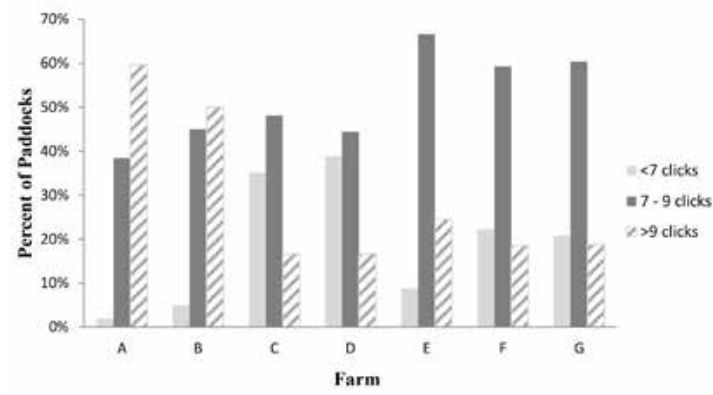

Figure 3 The proportion of paddocks in which post-grazing herbage mass was measured as $<7$ clicks (less than $3.5 \mathrm{~cm}$ ), between 7 and 9 clicks (3.4 to 4.5 $\mathrm{cm}$ ), or $>9$ clicks (greater than $4 \mathrm{~cm}$ ) on a rising plate meter, on seven case study farms between August 2012 and May 2013.

Grazing lower yields than this range will reduce pasture growth and can impact on short-term animal intake while grazing higher yields than this range will harm sward characteristics such as leaf proportion and also reduce milk production (Curran et al. 2010; Holmes et al. 1992).

A large range in post-grazing residuals both between and within farms was found (Figure 3), highlighting the variability of grazing residuals within these farms, along with significant lost opportunity on farm. Farms A and $\mathrm{B}$, with high proportions of post-grazing residuals $>9$ clicks or $4.5 \mathrm{~cm}$ average height, indicate situations of wasted pasture, reduced pasture quality (Stakelum \& Dillon 2007) and decreased animal performance. In contrast, Farms $\mathrm{C}$ and $\mathrm{D}$, with high proportions of post-grazing residuals $<7$ clicks or $3.5 \mathrm{~cm}$ average height, indicate situations where pasture growth and animal performance were suppressed through overgrazing. Ganche et al. (2013) found that grazing to $2.7 \mathrm{~cm}$ resulted in a significant reduction in milksolids production and grass DM intake compared to grazing to 3.5 or $4.2 \mathrm{~cm}$.

Ensuring that post-grazing residuals are managed 


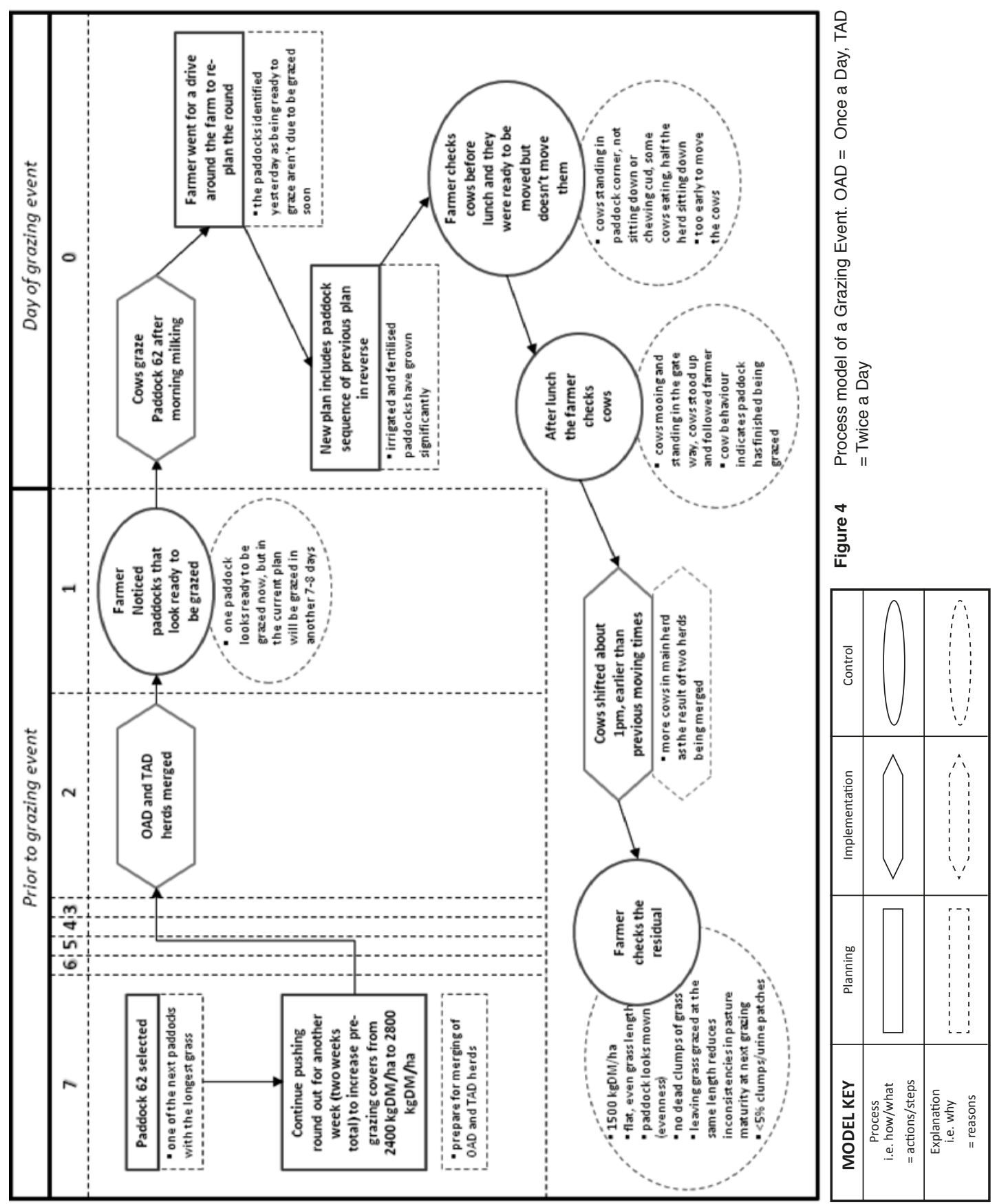

well and with consistency enables plants to capture as much sunlight energy as possible, and convert this into feed for cows. Such practice leads to high pasture growth rates and forage quality in the subsequent regrowth period, as tiller size and density adapt to a consistent light regime after each grazing, minimising the "lag" in the accumulation of new green leaf. Postgrazing residuals consistently lower than about $3.5 \mathrm{~cm}$ compressed height (7 clicks) reduces energy stores as ryegrass stores the majority of its water soluble carbohydrates below this (Fulkerson \& Donaghy 2001). Over-grazing results in a longer lag phase while plant energy status is rebuilt, and further restricts the size of the first re-growing leaf. Post-grazing residuals consistently higher than about $6 \mathrm{~cm}$ eventually result in reduced growth rates as more plant energy goes 
into stem elongation, and dead matter along with stem material shades out new tillers, thereby reducing tiller density. Chapman et al. (2014) estimate these poor grazing management decisions, grazing too early and not achieving target residuals, to cost farmers $\$ 600 / \mathrm{ha} /$ season.

Analysis of farmer decision making which took place at an operational level highlighted the complexity of the daily grazing management process. Figure 4 is an example of a grazing event that was observed and it highlights that grazing events are planned, implemented and controlled, but this is not necessarily a linear process. The actions taken during this management process varied between grazing events and between farmers, however some key management approaches used by both farmers were derived from the grazing events collectively. These were:

1. Recruitment of paddocks into a grazing plan

2. Shuffling of the paddock grazing sequence within the grazing plan

3. Management of individual grazing events; before, during and after the event

These key themes are discussed in further detail by Hirst et al. (2014), providing rural professionals an enhanced understanding of grazing management practices at an operational level and farmers an opportunity to consider their own process compared to others. Increased focus on the operational grazing management process will present an opportunity to further assess the management of the pre-grazing yield, grazing residuals and leaf-stage on-farm and identify effective approaches to manage these elements.

\section{Conclusions}

This case study highlights the potential to increase onfarm productivity through better grazing management practices. In essence, $49 \%$ of measured paddocks were grazed too soon based on leaf stage, $62 \%$ were grazed outside the recommended pre-grazing yield, and $48 \%$ of measured paddocks were not grazed to a desirable height. An improved understanding by rural professionals of grazing management decision making at an operational level would result in the generation of extension strategies which increase farmer engagement, adoption of technology and ultimately improve on-farm productivity.

\section{ACKNOWLEDGEMENTS}

The authors wish to acknowledge the farmers who participated in this study.

\section{REFERENCES}

Chapman, D.; McCarthy, S.; Kay, J. 2014. Hidden dollars in grazing management: Getting the most profit from your pastures. Proceedings of the SIDE conference: 21-36.

Curran, J.; Delaby, L.; Kennedy, E.; Murphy. J.P.; Boland, T.M.; O'Donovan, M. 2010. Sward characteristics, grass dry matter intake and milk production performance are affected by pre-grazing herbage mass and pasture allowance. Livestock Science 127: 144-154

DairyNZ FarmFact 1-2; Principles of grazing management. 2008. http://www.dairynz.co.nz/file/ fileid $/ 36113$

Dey, I. 1993. Qualitative data analysis: a user-friendly guide for social scientists. : Routledge, London

Donaghy, D.J. 1998. Improving the production and persistence of temperate pasture species in subtropical dairy regions of Australia. PhD Thesis. University of New England

Donaghy, D.J.; Fulkerson, W.J. 1998. Priority for allocation of water soluble carbohydrate reserves in Lolium perenne (L.). Grass and Forage Science 53: 211-218.

Ganche, E.; Delaby, L.; O’Donovan, M.; Boland, T.M.; Galvin, N.; Kennedy, E. 2013. Post-grazing sward height imposed during the first 10 weeks of lactation: Influence on early and total lactation dairy cow production, and spring and annual sward characteristics. Livestock Science 157: 299-311

Fulkerson, W.J.; Donaghy, D.J. 2001. Plant-soluble carbohydrate reserves and senescence - key criteria for developing an effective grazing management system for ryegrass-based pastures: a review. Australian Journal of Experimental Agriculture 41: 261-275.

Hirst, C.; McCarthy, S.; Donaghy, D.; Gray, D.; Wood, B. 2014. An insight into operational grazing management. DairyNZ Technical Series, Issue 23. http://www.dairynz.co.nz/page/pageid/2145878009/ Technical_Series

Hoogendoorn, C. J.; Holmes, C. W.; Chu A. C. P. 1988. Grazing management in spring and subsequent dairy cow performance. Proceedings of the New Zealand Grassland Association 49: 7-10

Holmes, C.W.; Hoogendoorn, C.J.; Ryan, M.P; Chu, A.C.P. 1992. Some effects of herbage composition, as influenced by previous grazing management, on milk production by cows grazing on ryegrass/white clover pastures. 1. Milk production in early spring: effects of different regrowth intervals during the preceding winter period. Grass and Forage Science 47: 309-315 
Lee, J.M.; Donaghy, D.J.; Sathish, P.; Roche, J.R. 2010. Perennial ryegrass regrowth after defoliation - physiological and molecular changes. Proceedings of the New Zealand Grassland Association 72: 127133.

Lee, J.; Hedley, P.; Roche, J. 2011 Grazing management guidelines for optimum pasture growth and quality. DairyNZ Technical Series, Issue 5. http://www.dairynz.co.nz/page/pageid/2145878009/ Technical_Series
Macdonald, K. A.; Glassey, C. B.; Rawnsley, R. P. 2010. The emergence, development and effectiveness of decision rules for pasture based dairy systems. pp. 199- 209 In: Meeting the challenges of pasturebased dairying. Eds. Edwards, G. R.; Bryant, R. H. Proceedings of the 4th Australasian Dairy Science Symposium. Available at: http://www.sciquest.org. nz/adss 2010

Stakelum, G.; Dillon, P. 2007. The effect of grazing pressure on rotationally grazed pasture in spring/ early summer on subsequent sward characteristics. Irish Journal of Agriculture and Food Research 46: 15-28. 